\title{
Numerical Analysis of Flow Field in Vertical Wind Turbine at Free- Stream Turbulence Region
}

\author{
Syaiful ${ }^{1 *}$, M. Ilham Maulana ${ }^{2}$, Nazaruddin Sinaga ${ }^{1}$, Rizky Djon Hansemit ${ }^{1}$ \\ ${ }^{1}$ Department of Mechanical Engineering, Universitas Diponegoro, Semarang 50275, Indonesia \\ * Corresponding author: syaiful.undip2011@gmail.com \\ ${ }^{2}$ Department of Mechanical Engineering, Syiah Kuala University, Banda Aceh 23111, Indonesia
}

\begin{abstract}
Air turbulence can affect the aerodynamic performance of wind turbines, and this effect is less on vertical wind turbines compared to horizontal wind turbines. In addition, vertical wind turbines have many advantages, but the literature related to their use to produce power is still small and needs to be developed. In this study, the effect of free-stream turbulence on the aerodynamic performance of Darrieus type vertical wind turbines was studied through two-dimensional numerical simulations. This performance can be observed through the power $(\mathrm{P})$ and turbine power coefficient $(\mathrm{Cp})$. Simulations were carried out at 5\% turbulent intensity $(\mathrm{Tu})$ with variations in wind speed $\left(\mathrm{U}_{\mathrm{oo}}\right)$. The turbulent model used was the standard k- $\varepsilon$ (SKE) and k- $\omega$ SST (SSTKW). The simulation results of the two turbulent models show the suitability for the power value $(\mathrm{P})$ and the coefficient $(\mathrm{Cp})$ to the experimental results The simulation result error reached $0.57 \%$ for $\mathrm{CP}$ with the standard $\mathrm{k}-\varepsilon$ turbulent model; $0.14 \%$ for $\mathrm{CP}$ with the $\mathrm{k}-\omega \mathrm{SST}$ model; $0.6 \%$ for $\mathrm{P}$ with the standard $\mathrm{k}-\varepsilon$ model; and $0.18 \%$ for P with the k- $\omega$ SST model.
\end{abstract}

Keywords: Wind turbine, Aerodynamics, Turbulence, Darrieus wind turbine.

\section{INTRODUCTION}

The aerodynamic performance of wind turbines can be affected by air turbulence. This performance can be shown from the wake turbine. The intensity of the turbine wake will decrease faster as turbulent intensity increases [1]. Furthermore, certain turbine wake characteristics can be a cause of power losses and increased fatigue loads in the turbine [2]. In addition to performance, air turbulence also affects loading on turbines [3], especially for horizontal wind turbines [4]. The effect of air turbulence is quite large for small scale wind turbines because the position of the turbine is closer to the ground. If the turbine is installed in a densely populated area, this position makes the turbine vulnerable to obstacles such as buildings or trees [5] which can disrupt air flow in the turbine rotor. This barrier raises the potential for higher turbulent intensity compared to turbines in quiet areas of the population [6].

Vertical axis wind turbines (VAWT) have several advantages compared to horizontal wind turbines, namely the structure is more balanced, less noisy, easier to adjust to architectural design [7], compact design, easily connected with gears or generators, easier blade control, and low levels of fatigue [8]. With these advantages, vertical axis wind turbines have the potential to continue to be utilized.

Research on power utilization in vertical wind turbines has not been done much. The usual approach to obtain power curves is to determine the output power by averaging the measured power from wind speed [9], but this method does not include the free-stream turbulence effect. In a study conducted by Kooiman and Tullis [10], vertical wind turbines were tested for energy production based on the influence of air velocity and changes in flow direction without the control of free-stream turbulence levels. The results obtained that the turbine output power varies with changes in speed, but independent of changes in direction. Output data in this study are divided into data groups, each data group is determined turbulent intensity and aerodynamic characteristics. This approach is very dependent on the output data sample size, so it is possible to obtain different results if the data sample size is different.

Based on research conducted by Kooiman and Tullis [10], testing with turbulent flow control is needed. Detailed analysis in the turbulence-free stream area around the vertical turbine blade is scarce. Therefore, this study aims to look at the effect of the intensity of free-stream turbulence on the aerodynamic performance of Darrieus type vertical wind turbines through two-dimensional numerical simulations. Some numerical investigations in various application have been reported by researchers [11-13] 
Syaiful et al., International Journal of Emerging Trends in Engineering Research, 8(6), June 2020, 2568- 2576

\section{PHYSICAL MODEL}

Simulations in this study refer to experiments conducted by Baloutaki, Carriveau, and Ting [14]. They conducted a vertical wind turbine type Darrieus experiment in an air column with a turbulent generator to see the effect of free-stream turbulence on turbine aerodynamic performance. The length of the tested air column is $1.8 \mathrm{~m}$. The size of the air column cross-section is $0.76 \mathrm{~m} \times 0.76 \mathrm{~m}$. Simulations were carried out on a small vertical wind turbine, model P10, produced by Shanghai Aeolus Windpower Technology Co., Ltd. (SAWT) [15]. This Darrieus type of wind turbine has five blades and is made of aluminum, as shown in Figure 1. These wind turbine blades have a custom airfoil profile. The coordinates of this airfoil profile are shown in Figure 2. The length of the blade chord and turbine height are $45 \mathrm{~mm}$ and $0.3 \mathrm{~m}$, respectively. The diameter of the turbine rotor is $0.3 \mathrm{~m}$. Each turbine blade is connected with a rotary shaft through two supporting rods at position 0.33 and 0.66 of the turbine height. Supporting rods made of aluminum with a square cross-section with a size of $2 \mathrm{~mm} \times 25 \mathrm{~mm}$.

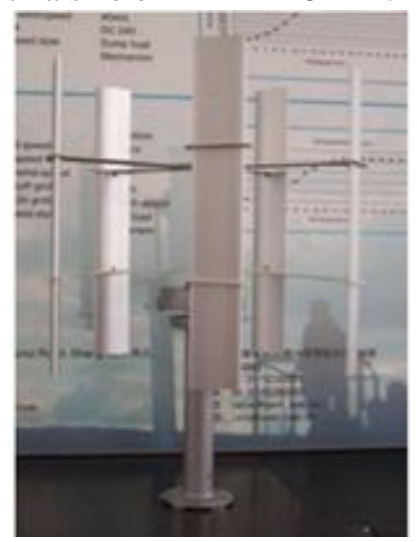

Figure 1 : Vertical wind turbine, model P10 (SAWT).

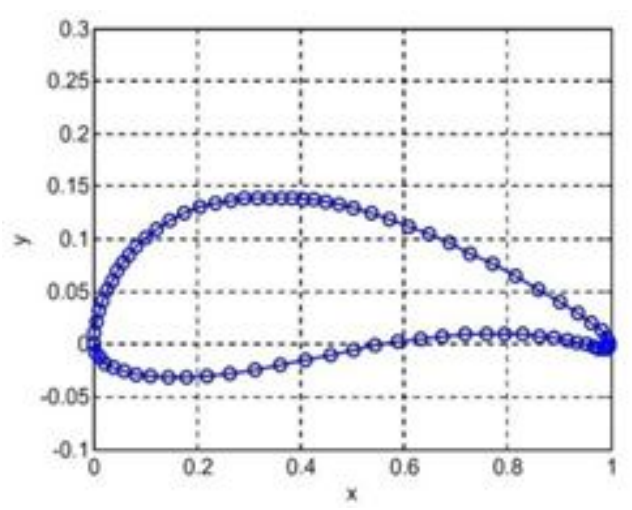

Figure 2 : Airfoil profile [14].

\section{MATHEMATICAL MODEL}

\subsection{Governing Equations}

The flow field around the vertical wind turbine has asymmetric, periodic, unsteady, separated, and turbulent characteristics [14]. The fluid flow builder equation represents the equation of conservation of mass, momentum, and energy [16]. The equation for the conservation of mass is shown in Eq. 1 [17]

$$
\frac{\partial \rho}{\partial t}+\frac{\partial(\rho w)}{\partial x}+\frac{\partial(\rho v)}{\partial y}+\frac{\partial(\rho w)}{\partial z}=0
$$

Eq. (1) is a three-dimensional mass conservation equation or continuity equation under compressible fluid conditions. This equation consists of two compilers on the left side, namely the rate of change in density with respect to time and mass flow rate out of control volume. In this study, the air is assumed to be incompressible, and simulations are carried out in the $\mathrm{XY}$ plane, then Eq. (1) becomes Eq. (2). u, v, and w are velocity vectors.

$$
\frac{a u}{\partial x}+\frac{\partial v}{\partial y}=0
$$

The conservation of momentum equation for the $\mathrm{x}$ and $\mathrm{y}$ directions is shown in Eq. 3 and 4. The equation for the $\mathrm{z}$-direction is not discussed because this study reviews the flow only in the XY plane. The left side of these equations shows the rate of increase in momentum per unit volume in the $\mathrm{x}$ and $\mathrm{y}$ directions. SMx and SMy are source terms such as body force caused by gravity. The energy conservation equation will not be discussed because, in this study, the temperature difference is very small.

For the standard k- $\varepsilon$ turbulent model (SKE), the turbulent kinetic energy $(\mathrm{k})$ and turbulent dissipation rate $(\varepsilon)$ are obtained from the transfer Eq. (5) and Eq.(6) [18]. Gk represents the formation of turbulent kinetic energy due to the average velocity gradient. Gb represents the formation of turbulent kinetic energy due to buoyancy. Buoyancy is a state characterized by the presence of non-zero gravitational fields and temperature gradients simultaneously.

In Eq.8, Prt is a turbulent Prandtl number for energy and gi is a component of the gravity vector in the $\mathrm{i}$-th direction. For the SKE turbulent model, the default value of Prt is $0.85 . \beta$ is the coefficient of thermal expansion. The degree showing the effect of buoyancy on $\varepsilon$ is determined by the constant $\mathrm{C} 3 \varepsilon$. In Eq. 10, $\mathrm{v}$ and $\mathrm{u}$ are components of flow velocity that are parallel to and perpendicular to the gravity vector. YM is dilatation dissipation. Mt is a turbulent Mach number. In Eq. (12), a is the speed of sound. $\sigma \mathrm{k}$ and $\sigma \varepsilon$ are turbulent Prandtl numbers for $\mathrm{k}$ and $\varepsilon$, respectively. Sk and $\mathrm{S} \varepsilon$ are user-defined source terms. $\mu \mathrm{t}$ is turbulent (eddy) viscosity. The default values for $\mathrm{C} 1 \varepsilon, \mathrm{C} 2 \varepsilon, \mathrm{C} \mu, \sigma \mathrm{k}$, and $\sigma \varepsilon$ are $1.44 ; 1.92 ; 0.09 ; 1$; and 1.3 , respectively.

$$
\rho \frac{\partial u}{D t}=\frac{\partial\left(-p+\tau_{x x}\right)}{\partial x}+\frac{d \tau_{y x}}{\partial y}+\frac{\partial \tau_{x x}}{\partial z}+S_{M x}
$$




$$
\begin{aligned}
& \rho \frac{\partial y}{\partial t}=\frac{d \tau_{x y}}{\partial x}+\frac{d\left(-p+\tau_{y y}\right)}{\partial y}+\frac{d \tau_{z y}}{\partial z}+S_{M y} \\
& \frac{\partial}{\partial t}(\rho h)+\frac{\partial}{\partial x_{i}}\left(\rho h u_{i}\right)= \\
& \frac{\partial}{\partial x_{j}}\left[\left(\mu+\frac{\mu_{K}}{\sigma_{\mathrm{h}}}\right) \frac{\partial x_{k}}{\partial x_{j}}\right]+G_{k}+C_{b}-\rho \varepsilon-Y_{M}+S_{k} \\
& \frac{\partial}{\partial t}(\rho s)+\frac{\partial}{\partial x_{i}}\left(\rho \varepsilon u_{i}\right)=
\end{aligned}
$$

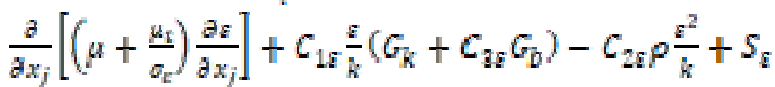

(6)

$$
\begin{aligned}
& G_{k}=-\rho \overline{u_{i}^{f} u_{j}^{g}} \frac{\partial u_{j}}{\partial x_{i}} \\
& G_{b}=\beta g_{i} \frac{\beta_{i}}{P_{r_{E}}} \frac{\partial T}{\partial x_{i}} \\
& \beta=-\frac{1}{p}\left(\frac{\partial p}{\partial T}\right) p \\
& C_{\mathrm{g} s}=\tanh \left|\frac{\mathrm{p}}{\mathrm{u}}\right| \\
& Y_{M}=2 \rho \varepsilon M_{\hat{\mathrm{t}}}^{2} 0 \\
& M_{\mathrm{t}}=\sqrt{\frac{k}{\mathrm{a}^{2}}} \\
& a=\sqrt{y R T} \\
& \mu_{t}=\rho C_{\mu} \frac{h^{2}}{\varepsilon}
\end{aligned}
$$

For the turbulent model k- $\omega$ SST (SSTKW), the turbulent kinetic energy $(\mathrm{k})$ and the specific turbulent dissipation rate $(\omega)$ are obtained from the transfer Eq.15 and Eq. (16) [18]. $\mathrm{G} \omega$ represents formation $\omega$. The value of $\mathrm{R} \omega$ is 2.95 . $\Gamma \mathrm{k}$ and $\Gamma \omega$ are effective diffusivity $\mathrm{k}$ and $\omega$. Yk and $\mathrm{Y} \omega$ are dissipation $\mathrm{k}$ and $\omega$ due to turbulence. Values $\zeta^{*}, \mathrm{R} \beta$, and $\beta \infty *$ are $1.5 ; 8$; and 0.09 . The value of $\mathrm{Mt} 0$ is 0.25 . $\mathrm{D} \omega$ is cross-diffusion. In Eq. 24, S is the strain rate. F1 and F2 are blending functions. In Eq. 28, y is the distance to the surface and $\mathrm{D} \omega+$ is the positive part of cross-diffusion.

$$
\begin{aligned}
& \frac{\partial}{\partial t}(\rho k)+\frac{\partial}{\partial x_{i}}\left(\rho k u_{i}\right)=\frac{\partial}{\partial x_{j}}\left(I_{k} \frac{\partial k}{\partial x_{j}}\right)+G_{k}-Y_{k}+S_{k} \\
& \frac{\partial}{\partial z}(\rho \omega)+\frac{\partial}{\partial x_{j}}\left(\rho \omega u_{j}\right)=\frac{\partial}{\partial x_{j}}\left(\mathrm{~T}_{\omega} \frac{\partial \omega}{\partial x_{j}}\right)+G_{\omega}-Y_{\omega}+D_{\omega}+S_{\omega} \\
& G_{\omega}=\frac{Q}{v_{i}} G_{k}
\end{aligned}
$$

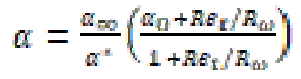

$$
\alpha^{*}=\alpha_{\infty}^{*}\left(\frac{\approx_{i}^{*}+R e_{i} / R_{k}}{1+R e_{i} / R_{k}}\right)
$$

$$
D_{\omega}^{+}=\max \left[2 \rho \frac{1}{\sigma_{\alpha h,}} \frac{1}{\omega} \frac{\partial h}{\partial x_{j}} \frac{\partial \omega}{\partial x_{j}}, 10^{-10}\right]
$$

$$
F_{2}=\tanh \left(\Phi_{2}^{2}\right)
$$

$$
\Phi_{z}=\max \left[2 \frac{\sqrt{h}}{0.09 \omega y}, \frac{300_{\mu}}{\rho y^{2} \omega}\right]
$$

$$
F\left(M_{t}\right)=\left\{\begin{array}{cc}
0 & M_{t} \leq M_{t 0} \\
M_{t}^{2}-M_{t 0}^{2} & M_{t}>M_{t 0}
\end{array}\right.
$$

$$
\begin{array}{r}
M_{t}^{2} \equiv \frac{3 \hbar z}{a^{x}} \\
\beta_{i}=F_{1} \beta_{i, 1}+\left(1-F_{1}\right) \beta_{i / 2}
\end{array}
$$


Syaiful et al., International Journal of Emerging Trends in Engineering Research, 8(6), June 2020, 2568- 2576

\subsection{Boundary conditions}

In this two-dimensional simulation, the computational domain boundary conditions consist of velocity inlet, outlet pressure, wall, and symmetry. The boundary conditions in the computational domain are shown in Eq. (40), (41) and (42). The values of wind speed, turbine rotational speed, power, and power coefficient used in the simulation are shown in Table 1. The computational domain is divided into three sub-domains, namely, sub-domains A, B, and C (see Figure 5). Sub-domain B is organized as moving mesh, while sub-domains $\mathrm{A}$ and $\mathrm{C}$ are managed as stationary mesh. The turbine blade surface was set as a non-slip wall. Simulations were carried out at a turbulent intensity $(\mathrm{Tu})$ of $5 \%$. The turbulent model used was the standard k- $\varepsilon$ (SKE) and k- $\omega$ SST (SSTKW).

$$
\begin{aligned}
& \text { Inlet } \quad u=U_{m}, v=0 \\
& \text { Outlet } \quad p=p_{a t m} \\
& \text { Wall } u=v=0
\end{aligned}
$$

\section{NUMERICAL METHOD}

Mesh in the computational domain was divided into moving mesh in the area around the turbine blade and stationary mesh in the inside and outside of the turbine. The mesh was reduced in the area around the blade and inside the turbine. Figure 3 shows the overall mesh detail. Figure 4 shows the mesh around the turbine blade. The mesh used was a hybrid mesh consisting of structured and triangle mesh, as shown in Figure 7. The hybrid mesh is a type of mesh that is good in terms of accuracy and automation [19]. The number of mesh was 958124 cells.

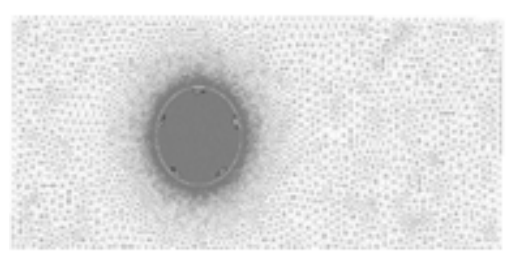

Figure 3: Mesh of the whole computational domain

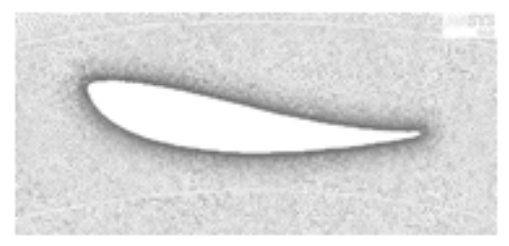

Figure 4: Mesh around the turbine blade

\begin{tabular}{|c|c|c|c|c|c|}
\hline No. & $\mathbf{U}_{\infty}(\mathbf{m} / \mathbf{s})$ & n (rpm) & $P$ (Watt) & $\lambda$ & $\mathrm{Cp}$ \\
\hline 1 & 3.0441 & 13.8495 & 0.0227 & 0.0714 & $\begin{array}{r}0.000 \\
2\end{array}$ \\
\hline 2 & 3.4125 & 21.1520 & 0.0227 & 0.0973 & $\begin{array}{r}0.000 \\
2\end{array}$ \\
\hline 3 & 3.7809 & 28.2027 & 0.0227 & 0.1171 & $\begin{array}{r}0.000 \\
5 \\
\end{array}$ \\
\hline 4 & 4.1929 & 33.2389 & 0.0227 & 0.1245 & $\begin{array}{r}0.000 \\
9\end{array}$ \\
\hline 5 & 4.4256 & 35.5052 & 0.0227 & 0.1260 & $\begin{array}{r}0.000 \\
9\end{array}$ \\
\hline 6 & 4.8861 & 42.8077 & 0.0227 & 0.1375 & $\begin{array}{r}0.001 \\
2 \\
\end{array}$ \\
\hline 7 & 5.2109 & 49.8584 & 0.0202 & 0.1502 & $\begin{array}{r}0.001 \\
4\end{array}$ \\
\hline 8 & 5.4823 & 57.1608 & 0.0227 & 0.1637 & $\begin{array}{r}0.002 \\
1\end{array}$ \\
\hline 9 & 5.9476 & 66.7296 & 0.0454 & 0.1761 & $\begin{array}{r}0.002 \\
6 \\
\end{array}$ \\
\hline 10 & 6.4033 & 81.3346 & 0.0681 & 0.1994 & $\begin{array}{r}0.003 \\
5 \\
\end{array}$ \\
\hline 11 & 6.7765 & 90.6516 & 0.0681 & 0.2100 & $\begin{array}{r}0.004 \\
0\end{array}$ \\
\hline 12 & 7.1013 & 112.3072 & 0.1159 & 0.2483 & $\begin{array}{r}0.006 \\
1\end{array}$ \\
\hline 13 & 7.5133 & 167.4536 & 0.2848 & 0.3499 & $\begin{array}{r}0.012 \\
4 \\
\end{array}$ \\
\hline 14 & 7.7896 & 191.3755 & 0.3831 & 0.3857 & $\begin{array}{r}0.015 \\
2\end{array}$ \\
\hline 15 & 8.1580 & 220.3336 & 0.5495 & 0.4240 & $\begin{array}{r}0.018 \\
5 \\
\end{array}$ \\
\hline 16 & 8.6670 & 310.9852 & 1.3182 & 0.5633 & $\begin{array}{r}0.037 \\
6 \\
\end{array}$ \\
\hline 17 & 9.0354 & 335.1590 & 1.6736 & 0.5824 & $\begin{array}{r}0.042 \\
6 \\
\end{array}$ \\
\hline 18 & 9.3553 & 351.7784 & 2.0844 & 0.5904 & $\begin{array}{r}0.047 \\
5\end{array}$ \\
\hline 19 & 9.6801 & 392.5716 & 2.6112 & 0.6367 & $\begin{array}{r}0.053 \\
8 \\
\end{array}$ \\
\hline 20 & 9.9127 & 435.8829 & 3.2565 & 0.6904 & $\begin{array}{r}0.062 \\
4 \\
\end{array}$ \\
\hline 21 & 10.4169 & 483.7268 & 4.0252 & 0.7291 & $\begin{array}{r}0.066 \\
7\end{array}$ \\
\hline 22 & 10.8337 & 526.7863 & 4.7889 & 0.7634 & $\begin{array}{r}0.070 \\
4 \\
\end{array}$ \\
\hline 23 & 11.1537 & 558.0107 & 5.3888 & 0.7855 & $\begin{array}{r}0.073 \\
0\end{array}$ \\
\hline 24 & 11.5221 & 586.7170 & 5.9382 & 0.7995 & $\begin{array}{r}0.072 \\
8\end{array}$ \\
\hline 25 & 11.8905 & 615.4234 & 6.6087 & 0.8126 & $\begin{array}{r}0.073 \\
5 \\
\end{array}$ \\
\hline 26 & 12.2637 & 646.6478 & 7.2791 & 0.8278 & $\begin{array}{r}0.073 \\
9 \\
\end{array}$ \\
\hline
\end{tabular}

Table 1: Data on wind speed, turbine rotational speed, power, and power coefficient [14]. 
Syaiful et al., International Journal of Emerging Trends in Engineering Research, 8(6), June 2020, 2568- 2576

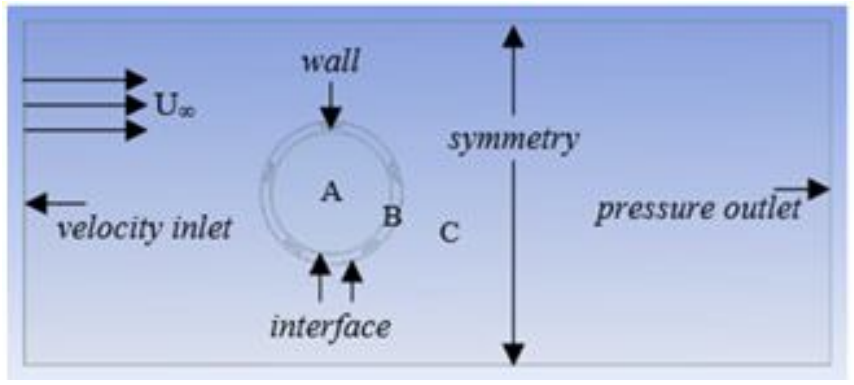

Figure 5: Computational domain and boundary conditions.

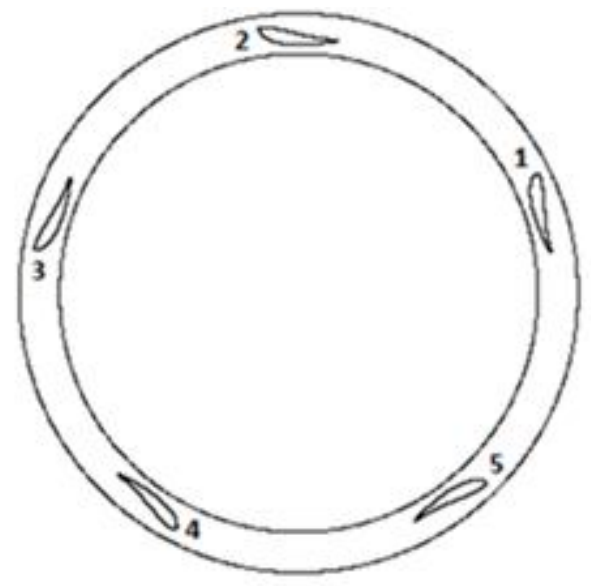

Figure 6: Position number of turbine blade

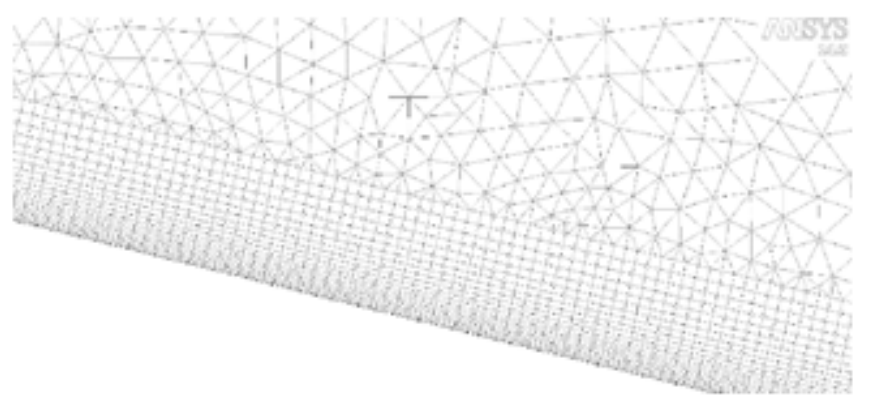

Figure 7: Mesh detail around the turbine blade surfaces

Some amount of mesh has been tested to obtain an independent mesh. Independent mesh indicates that the addition of the next mesh number no longer influences the simulation results. From the results of mesh testing, independent mesh has a total of 958124 elements.

The spatial discretization used is the second-order upwind for the momentum equation, the first order upwind for the turbulent equation, the least-squares cell-based for the gradient, and the standard for pressure. The pressure-velocity coupling used is SIMPLEC (Semi Implicit Method for Pressure Linked Equations Consistent). The iteration process residue is set to 0.0001 for the equation of continuity, momentum, and turbulence.

\section{RESULT AND DISCUSSION}

\subsection{Validation}

The numerical simulation results of this study were validated with experimental data conducted by Baloutaki, Carriveau, and Ting [14]. The parameters compared are turbine power and power coefficient. The turbine power coefficient was calculated by Eq. (43) [20]. Turbine power was calculated by Eq. (44) [21]. Cm is the moment coefficient obtained from the iteration results. $\lambda$ is the tip speed ratio. $\lambda$ shows the ratio between turbine rotational speed and free-stream airspeed, see Eq. (45) [22]. $\rho$ is the density of air, $R$ is the radius of the turbine rotor, $\mathrm{h}$ is the height of the turbine rotor.

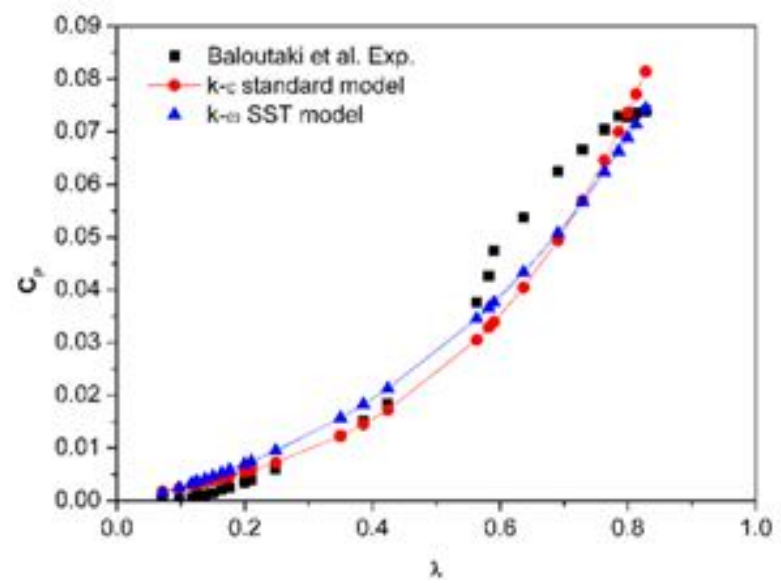

Figure 8: Comparison of turbine power coefficient between simulation and experiment Comparison of turbine power coefficient between simulation and experiment

Figures 8 and 9 show that the simulation results of the two turbulent models have the same tendency in increasing $\mathrm{CP}$ and P. Simulation of wind turbines with CFD is usually done at transient conditions to see transient effects [22]. The simulation in this study was carried out on a steady-state to observe the results of $\mathrm{CP}$ and $\mathrm{P}$ wind turbines. The results showed that the simulation on the steady-state for wind turbines was not good.

The results showed a match between the results of simulations and experiments for several values of tip speed ratio. In some tip speed ratios, the power simulation results and the power coefficient exceed the experimental results, and this is due to the limitations of two-dimensional modeling [23, 24]. Besides, this excess power and coefficient of power are also due to the use of a fully turbulent RANS (Reynolds Average Navier-Stokes) model for low Reynolds numbers [25]. Two-dimensional modeling does not take into account three-dimensional effects such as vortex tips and irregular pressure distribution on three-dimensional blades. 


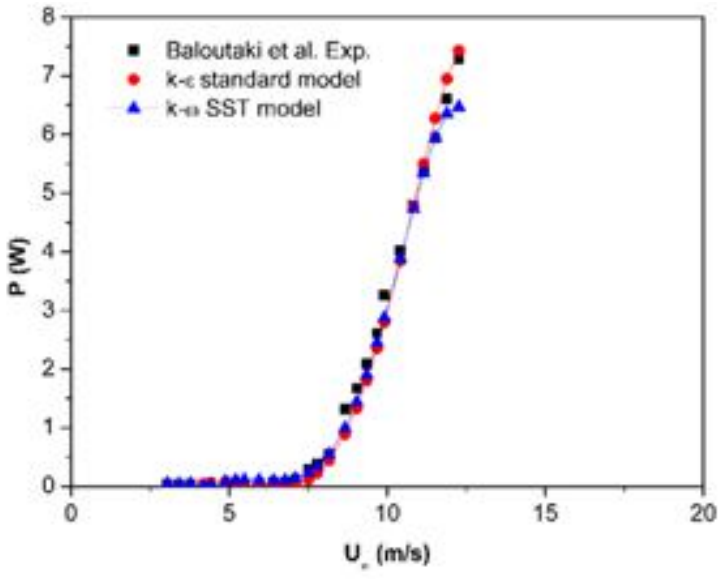

Figure 9: Comparison of turbine power between simulation and experiment.

$$
\begin{gathered}
C_{P}=C_{m} \times \lambda \\
P=\frac{1}{2} \times \rho \times\left(U_{s}{ }^{3}\right) \times 2 \times R \times h \times C_{P} \\
\lambda=\frac{n R}{U_{m}}
\end{gathered}
$$

\subsection{Velocity Field Distribution}

The parameters observed from the simulation results are the distribution of speed, turbulent kinetic energy, and pressure in the area around the turbine rotor. Figures 10 and 11 show the velocity vector distribution of the simulation results of the turbulent model $\mathrm{k}-\varepsilon$ standard and $\mathrm{k}-\omega \mathrm{SST}$ at wind speeds of 3.04 and $12.26 \mathrm{~m} / \mathrm{s}$. The figure shows the vortex formed in the wake blade area 3 and 4, both at low and high free-stream speeds. The greater the angle of attack, the boundary layer will be more difficult to continue to stick to the surface of the airfoil, and the separation area will be even greater [26]. This flow separation causes vortex [27].

At free-stream speeds of $3.04 \mathrm{~m} / \mathrm{s}$, the number of vortexes formed each pair in the wake area of blades 3 and 4 . Each pair of vortices has the opposite direction. This is consistent with research conducted by Fujisawa and Shibuya [28]. However, the two pairs of the vortex have different shapes between the two turbulent models. In the standard k- $\varepsilon$ turbulent model, the larger vortex in the wake blade 3 area looks closer to the center of the turbine. Whereas on blade 4 , the vortex that is closer to the surface of the blade appears to be stretching. In the k-ST SST model, the larger vortex in the wake blade three areas is seen moving away from the center of the turbine.

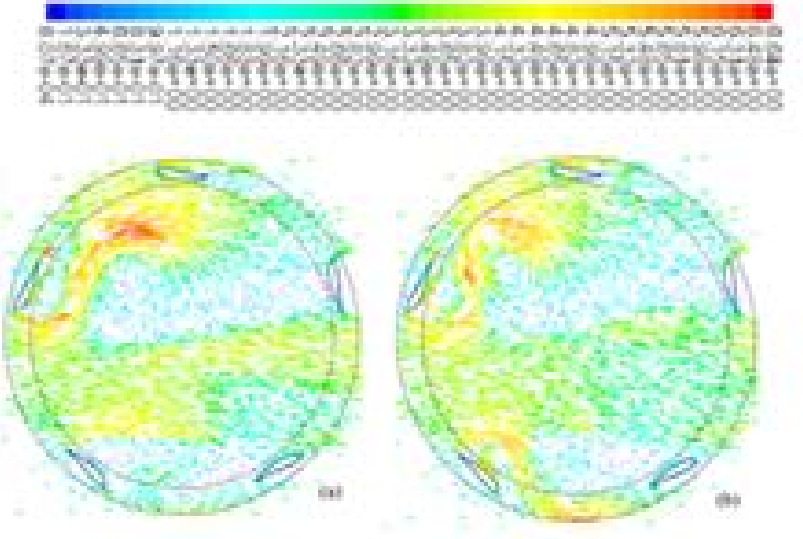

Figure 10: Velocity vector $(\mathrm{m} / \mathrm{s})$ at $U=3.04 \mathrm{~m} / \mathrm{s}$. (a) standard $\mathrm{k}-\varepsilon$ , (b) k- $\omega$ SST
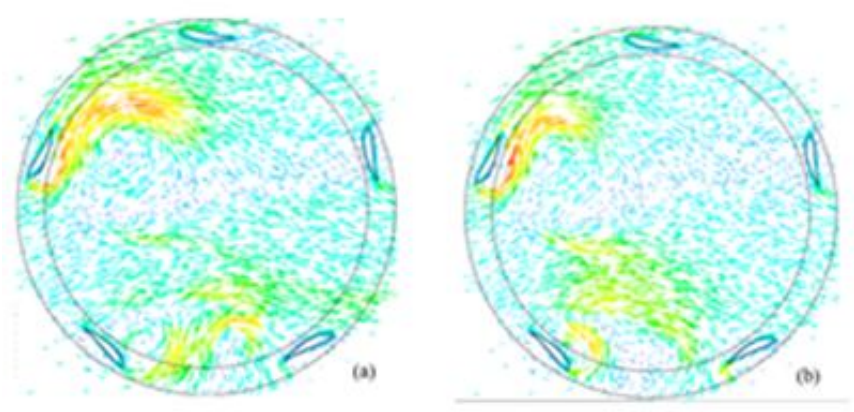

Figure 11: Velocity vector $(\mathrm{m} / \mathrm{s})$ at $U=12.26 \mathrm{~m} / \mathrm{s}$. (a) standard k$\varepsilon$, (b) k- $\omega$ SST

At a free-stream speed of $12.26 \mathrm{~m} / \mathrm{s}$, the vortex pair in the wake blade 3 area gets closer to the blade so that it appears that one of the vortexes, which is a smaller vortex, has decreased in size due to the insistence of a larger vortex. The closer the vortex pair to blade 3 , causing the interaction of the blade-vortex, which causes an increase in wind turbine power [28]. The vortex pair in the wake blade three regions also appears to have a different shape between the two turbulent models. One vortex closer to the center of the turbine appears larger on the standard k- $\varepsilon$ model than $\mathrm{k}-\omega$ SST. On wake blade 4 , the standard $\mathrm{k}-\varepsilon$ model shows more vortices than the $\mathrm{k}-\omega \mathrm{SST}$ model.

It can be said that the formation of vortex is influenced by free-stream speed, or in other words, is influenced by tip speed ratio. The velocity vector results also show different flow conditions at each blade.

In the area inside the turbine, the same two turbulent models show a decrease in speed, both at 3.04 and $12.26 \mathrm{~m} / \mathrm{s}$ free-stream speed. This is consistent with research conducted by Guilherme Silva [29]. This decrease in speed is clearly 
Syaiful et al., International Journal of Emerging Trends in Engineering Research, 8(6), June 2020, 2568- 2576

seen in the wake area of the turbine blade, which is shown in blue. This decrease in speed indicates that the simulation results are in accordance with existing physical phenomena.

\subsection{Turbulent Kinetic Energy Distribution}

The distribution of turbulent kinetic energy around the turbine rotor is shown in Figures 12 and 13. Figure 12 shows the turbulent kinetic energy contours of the two turbulent models at wind speeds of $3.04 \mathrm{~m} / \mathrm{s}$. Figure 13 shows the turbulent kinetic energy contour at a wind speed of $12.26 \mathrm{~m} /$ s. This contour shows that each blade produces different turbulent levels. This turbulence then carries along the wake that is generated until it slowly disappears. This shows that the eddy structure in the flow is gradually anticipated [30].
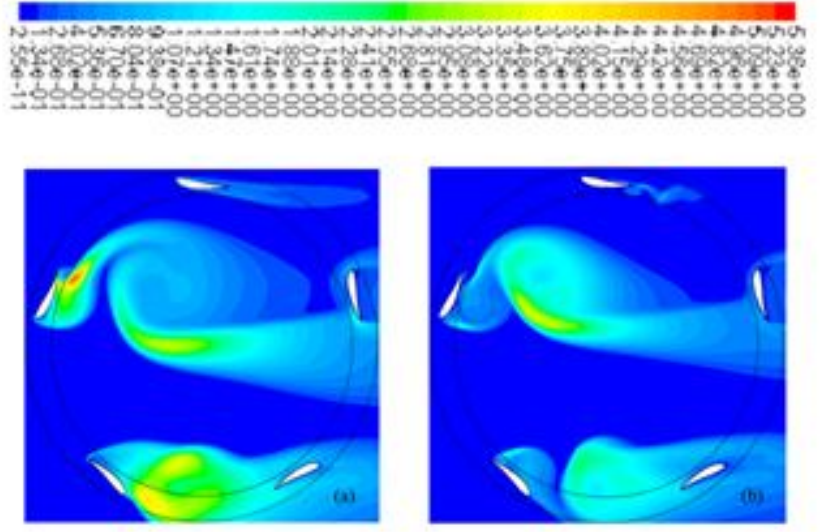

Figure 12: Turbulent kinetic energy contours $\left(\mathrm{m}^{2} / \mathrm{s}^{2}\right)$ at $U=3.04$ $\mathrm{m} / \mathrm{s}$. (a) standard k- $\varepsilon$, (b) k- $\omega$ SST.

Areas with high turbulent kinetic energy indicate complex turbulent flow such as slip flow [30]. Turbulent kinetic energy contours in the turbine sweep area increase with increasing turbine rotational speed. This shows that the turbine rotational speed has an influence on the flow field structure [30].
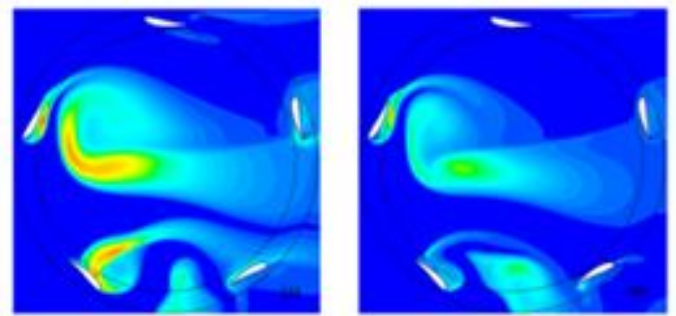

Figure 13: Turbulent kinetic energy contours $\left(\mathrm{m}^{2} / \mathrm{s}^{2}\right)$ at $\mathrm{U}=12.26$ $\mathrm{m} / \mathrm{s}$. (a) standard k- $\varepsilon$, (b) k- $\omega$ SST

\subsection{Pressure Distribution}

The distribution of pressure around the turbine rotor is shown in Figures 14 and 15. Figure 14 shows the pressure contours of the two turbulent models at a wind speed of $3.04 \mathrm{~m} / \mathrm{s}$. Figure 15 shows the pressure contour at a wind speed of 12.26 $\mathrm{m} / \mathrm{s}$. Pressure drops around the rotor are clearly visible on blades 3 and 4, shown in blue in the waking area. This pressure drop occurs because of the transfer of energy to the turbine blade [31] so that it is converted to power [32].
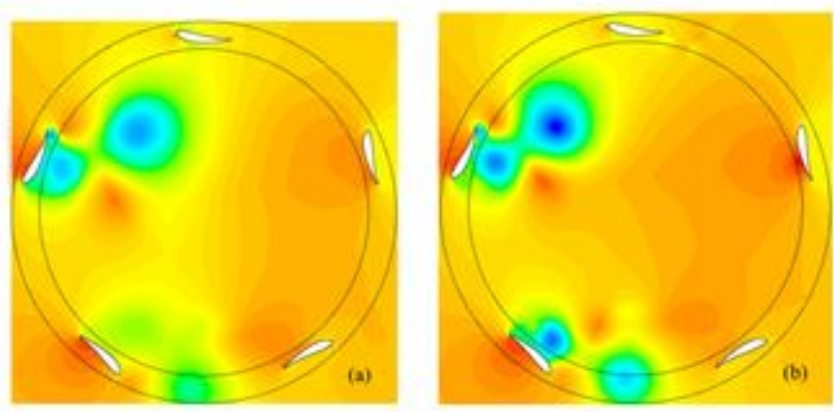

Figure 14: Pressure contour $(\mathrm{Pa})$ at $\mathrm{U}=3.04 \mathrm{~m} / \mathrm{s}$. (a) standard $\mathrm{k}-\varepsilon$, (b) k- $\omega$ SST.

The region with high pressure is located on the upstream blade, while areas with lower pressure are located on the downstream blade. The low-pressure region in the wake blade 3 and 4 has a correlation with the high-speed vortex shown in Figures 10 and 11 . This shows the suitability between the velocity and pressure distribution.

Pressure distribution indicates the area with non-uniform pressure in the path of the turbine blade and the blade facing the direction of flow [31]. This pressure greatly contributes to the torque produced. A high-pressure area on the side of the turbine blade facing the direction of flow will increase turbine rotation, which contributes to increase torque.
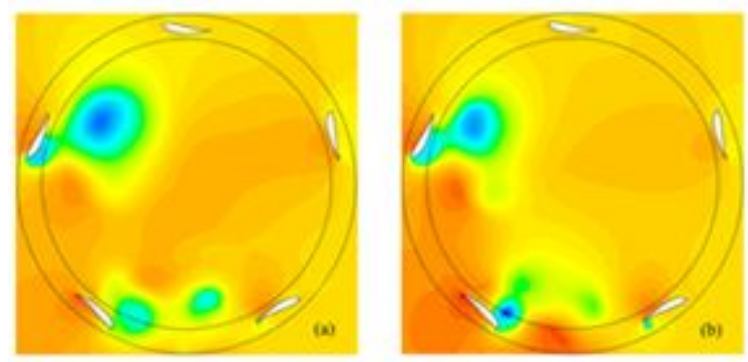

Figure 15: Pressure contour $(\mathrm{Pa})$ at $\mathrm{U}=12.26 \mathrm{~m} / \mathrm{s}$. (a) standard k- $\varepsilon$, (b) k- $\omega$ SST.

\section{CONCLUSION}

In this research, a two-dimensional simulation of a Darrieus type vertical wind turbine was carried out under steady conditions to observe the performance of a wind turbine, 
Syaiful et al., International Journal of Emerging Trends in Engineering Research, 8(6), June 2020, 2568- 2576

namely $\mathrm{CP}$ and $\mathrm{P}$. To approach the actual physical condition of the turbine, the computational domain used a moving mesh in the area around the turbine blade. Independent mesh was obtained after the mesh testing process several times.

The simulation results using the turbulent model k- $\varepsilon$ standard and k- $\omega$ SST showed compatibility with $\mathrm{CP}$ and $\mathrm{P}$ experiments. But on some tip speed ratio values, the $\mathrm{CP}$ and $\mathrm{P}$ values exceed the experimental results, and this was due to the limitations of two-dimensional modeling that does not take into account three-dimensional effects such as tip vortex. So the authors suggest applying three-dimensional modeling for the case of wind turbines in further research.

The observed flow field included the distribution of velocity, turbulent kinetic energy, and pressure. The distribution of velocity vectors showed the presence of vortices that are in accordance with previous studies and proves that vortex formation was affected by the tip speed ratio. Turbulent kinetic energy distribution successfully showed the influence of turbine rotational speed on turbulent kinetic energy. Likewise, the distribution of stresses can indicate actual physical phenomena.

\section{ACKNOWLEDGEMENT}

Acknowledgments are addressed to Diponegoro University's Mechanical Engineering Thermofluid Laboratory for its assistance in providing the simulation facilities needed in this study and Department of Mechanical Engineering of Syiah Kuala University for the collaboration.

\section{NOMENCLATURE}

$\mathrm{u} \quad \mathrm{x}$-axis velocity vector

$\mathrm{v} \quad \mathrm{y}$-axis velocity vector

w $\mathrm{z}$-axis velocity vector

$\mathrm{Tu}$ turbulent intensity

$\mathrm{U} \square$ turbulence free-stream velocity

$\mathrm{k}$ turbulent kinetic energy

$\varepsilon \quad$ turbulent dissipation rate

Gk the formation of $\mathrm{k}$ due to the average velocity gradient

$\mathrm{Gb}$ the formation of $\mathrm{k}$ due to buoyancy

Prt turbulent Prandtlnumbers for energy

gi the gravity vector component in the i-direction

$\beta$ coefficient of thermal expansion

$\mathrm{C} 3 \varepsilon$ degree of influence of buoyancy on $\varepsilon$

YM dilated dissipation

Mt turbulent Mach numbers

a speed of sound

$\sigma \mathrm{k}$ Prandtl number for $\mathrm{k}$

$\sigma \varepsilon$ Prandtl numbers for $\varepsilon$

Sk user-defined source term for $\mathrm{k}$

SE user-defined source term for $\varepsilon$

$\mu \mathrm{t}$ turbulent viscosity

$\omega$ turbulent specific dissipation rate
$\mathrm{G} \omega$ formation of $\omega$

$\Gamma \mathrm{k}$ effective diffusivity $\mathrm{k}$

$\Gamma \omega$ effective diffusivity $\omega$

$\mathrm{Yk}$ dissipation $\mathrm{k}$ due to tubulence

$\mathrm{Y} \omega$ dissipation $\omega$ due to turbulence

$\mathrm{D} \omega$ cross diffusion

$\mathrm{S}$ strain rate

F1, F2 blending function

$y$ distance to the surface

$\mathrm{D} \omega+$ positive part of cross diffusion

$\mathrm{p}$ outlet pressure

$\mathrm{n}$ turbine rotational speed

$\mathrm{P}$ turbine power

$\mathrm{P}=0,5 \times \rho \times($ 『U_$\infty \rrbracket \wedge 3) \times 2 \times \mathrm{R} \times \mathrm{h} \times \mathrm{C} \_\mathrm{P}$

$\rho$ air density

$\mathrm{h}$ turbine blade height

$\lambda$ tip speed ratio $\lambda=(\mathrm{nR}) / \mathrm{U}_{-} \infty$

$\mathrm{R}$ turbine radius

$\mathrm{CP}$ turbine power coefficient $\mathrm{C} \_\mathrm{P}=\mathrm{C} \_\mathrm{m} \times \lambda$

$\mathrm{Cm}$ turbine moment coefficient

VAWT vertical axis wind turbine

SKE standard $\mathrm{k}-\varepsilon$

SSTKW shear stress transport k- $\omega$

\section{REFERENCES}

1. A. Englberger, and A. Dörnbrack. Impact of Neutral Boundary-Layer Turbulence on Wind-Turbine Wakes: A Numerical Modelling Study. Boundary-Layer Meteorology, 162(3), 427-449, 2017. doi:10.1007/s10546-016-0208-z.

2. P. McKay, R. Carriveau, and D. Ting. Wake impacts on downstream wind turbine performance and yaw alignment, Wind Energy, 16(2), 221-234, 2013. doi:10.1002/we.544.

3. I. Abdallah, A. Natarajan, and J.D. Sørensen. Influence of the control system on wind turbine loads during power production in extreme turbulence: Structural reliability, Renewable Energy, 87, 464-477, 2016. doi:10.1016/j.renene.2015.10.044

4. C. Galinos, T. Larsen, H. Madsen, And U. Paulsen. Vertical Axis Wind Turbine Design Load Cases Investigation and Comparison with Horizontal Axis Wind Turbine, Energy Procedia, 94, 319-328, 2016. doi:10.1016/j.egypro.2016.09.190.

5. A. Araújo, D. Valença, A. Asibor, and P. Rosas. An approach to simulate wind fields around an urban environment for wind energy application, Environmental Fluid Mechanics, 13(1), 33-50 2013. doi:10.1007/s10652-012-9258-Z

6. B. Grieser, Y. Sunak, and R. Madlener. Economics of small wind turbines in urban settings: An empirical investigation for Germany, Renewable Energy, 78, 334-350, 2015. doi:10.1016/j.renene.2015.01.008.

7. M. Bhutta, N. Hayat, A. Farooq, Z. Ali, S.R. Jamil, and Z. Hussain. Vertical axis wind turbine - A review of various configurations and design techniques, 
Syaiful et al., International Journal of Emerging Trends in Engineering Research, 8(6), June 2020, 2568- 2576

Renewable and Sustainable Energy Reviews.16(4), 1926-1939, 2012. doi:10.1016/j.rser.2011.12.004.

8. T. Abu-El-Yazied, H.N. Doghiem, and A.M. Ali. Investigation of the Aerodynamic Performance of Darrieus Vertical Axis Wind Turbine, IOSR Journal of Engineering, 4(5), 18-29, 2014. doi:10.9790/3021-04571829.

9. J. Gottschall, and J. Peinke. Stochastic modelling of a wind turbine's power output with special respect to turbulent dynamics - art. no. 012045, Journal of Physics: Conference Series, 75(1), 012045, 2007. doi:10.1088/1742-6596/75/1/012045.

10. S.J. Kooiman, and S.W. Tullis. Response of a vertical axis wind turbine to time varying wind conditions found within the urban environment, Wind Engineering, 34(4), 389-401, 2010. doi:10.1260/0309-524X.34.4.389.

11. B. Suresh, K.N. Sathvik, S. Imran, O. V. Gopi Reddy, V.G. Tilak, A. Vijayalakshmi and V. S. Ghali, Diagnosing Osteoporosis through Numerical Simulation of Bone Sample by Non-Stationary Thermal Wave Imaging, International Journal of Emerging Trends in Engineering Research, 8(3), 776 779, 2020. https://doi.org/10.30534/ijeter/2020/27832020

12. E. Julianto, W.A. Siswanto and M. Effendy, Characteristics of Temperature changes and Stress of Float Glass under Heat Radiation, International Journal of Emerging Trends in Engineering Research, 7(9), 228 - 233, 2019.

https://doi.org/10.30534/ijeter/2019/03792019

13. E.I. Trubilin, S.I. Borisova, V.I. Konovalov, M.I. Chebotarev and A.D. Gumbarov, Experimental Studies of Parameters of Pneumatic Slot Sprayer, International Journal of Emerging Trends in Engineering Research, 8(1), 170 - 176, 2020. https://doi.org/10.30534/ijeter/2020/23812020

14. M. Ahmadi-Baloutaki, R. Carriveau, and D.S.K. Ting. Performance of a vertical axis wind turbine in grid generated turbulence, Sustainable Energy Technologies and Assessments. 11, 178-185, 2015. doi:10.1016/j.seta.2014.12.007.

15. SAWT, "P10 Vertical Axis Wind Turbine (VAWT)," Shanghai Aeolus Windpower Technology Co., Ltd.,. [Online]. Available: http://www.sawt.com.cn/.

16. M. Zamani, M.J. Maghrebi, and S.R. Varedi. Starting torque improvement using $\mathbf{J}$-shaped straight-bladed Darrieus vertical axis wind turbine by means of numerical simulation, Renewable Energy, 95, 109-126, 2016. doi:10.1016/j.renene.2016.03.069

17. H. Versteeg, H, and W. Malalasekera. An Introduction to Computational Fluid Dynamic: The Finite Volume Method, 1995.

18. D. Wilcox. Turbulence modeling for CFD, Turbulence Modeling for CFD. 2, 2006.

19. T.J. Baker, . Mesh generation: Art or science, Program Aerospace Science, 41(1), 29-63, 2005.
20. N.A. Samiran, A.A. Wahab, S. Mohd, and N. Rosly. Simulation Study on the Performance of Vertical Axis Wind Turbine, Applied Mechanics and Materials, 465-466, 270-274, 2014. doi:10.4028/www.scientific.net/AMM.465-466.270.

21. S. Brusca, R. Lanzafame, and M. Messina. Design of a vertical-axis wind turbine: how the aspect ratio affects the turbine's performance, International Journal of Energy and Environmental Engineering, 5(4), 333-340, 2014. doi:10.1007/s40095-014-0129-x.

22. T.J. Carrigan, B.H. Dennis, Z.X. Han, and B.P. Wang. Aerodynamic Shape Optimization of a Vertical-Axis Wind Turbine Using Differential Evolution, ISRN Renewable Energy, 2012. doi:10.5402/2012/528418.

23. M.R. Castelli, A. Englaro, and E. Benini. The Darrieus wind turbine: Proposal for a new performance prediction model based on CFD, Energy, 36(8), 4919-4934, 2011. doi:10.1016/j.energy.2011.05.036

24. P. Sabaeifard, H. Razzaghi, and A. Forouzandeh. Determination of Vertical Axis Wind Turbines Optimal Configuration through CFD Simulations, International Conference Future on Future Environment and Energy, 28, 109-113, 2012.

25. R. Lanzafame, S. Mauro, and Messina. M.2D CFD modeling of H-Darrieus Wind Turbines using a transition turbulence model, Energy Procedia, 45,131-140, 2014. doi: 10.1016/j.egypro.2014.01.015

26. I.H. Abbott, and A.E. Von Doenhoff. Theory of wing sections: including a summary of airfoil data, 2012.

27. Y.A. Cengel, and J.M. Cimbala. Fluid Mechanics, Fundamentals and Applications, 2006.

28. N. Fujisawa, and S. Shibuya. Observations of dynamic stall on Darrieus wind turbine blades, Journal of Wind Engineering and Industrial Aerodynamics, 89(2), 201-214, 2001. doi:10.1016/S0167-6105(00)00062-3.

29. G. Silva. Vertical axis wind turbine development. US Departement of Energy, 3, 1-10.

30. L. Cao, H. Wang, Y. Ji, Z. Wang, and W. Yuan. Analysis on the influence of rotational speed to aerodynamic performance of vertical axis wind turbine, Procedia Engineering. $\quad 31, \quad 245-250, \quad 2012$. doi:10.1016/j.proeng.2012.01.1019.

31. A. Shahzad, T. Asim, R. Mishra, and A. Paris. Performance of a Vertical Axis Wind Turbine under Accelerating and Decelerating Flows, Procedia CIRP, 11, 311-316, 2013. doi:10.1016/j.procir.2013.07.006.

32. R. Gupta, and A. Biswas. Computational fluid dynamics analysis of a twisted three-bladed H-Darrieusrotor, Journal of Renewable and Sustainable Energy, 2(4), 043111, 2010. doi:10.1063/1.3483487. 